\title{
COMPONENTES MORFOLÓGICOS DO MILHO COM MODELOS DE RODA COMPACTADORA, CARGAS VERTICAIS E LÂMINAS DE IRRIGAÇÃO
}

\author{
Morphological components of with models of press wheel, vertical loads and irrigation blades
}

\author{
Jorge Wilson Cortez ${ }^{1}$, Carlos Eduardo Angeli Furlani², Rouverson Pereira da Silva², Victor Zeitoum²
}

\begin{abstract}
RESUMO
Conduziu-se este trabalho, com o objetivo de avaliar três modelos de rodas compactadoras de semeadoras, dois níveis de carga vertical sobre as mesmas e duas lâminas de irrigação durante os períodos de pré e pós-emergência das plântulas de milho. O ensaio foi conduzido na UNESP de Jaboticabal, com o delineamento inteiramente casualizado (DIC) no esquema fatorial 3x2x2, combinando de três modelos de rodas compactadoras (roda lisa com estria, roda lisa com nervura e roda duplo angulada), com dois níveis de carga (162 N e $260 \mathrm{~N}$ ) e dois teores de água ( 15 e $19,5 \mathrm{~mm} \mathrm{dia}^{-1}$ ) sob três repetições. Os parâmetros analisados foram: produtividade, número de grãos por espiga, massa de 100 grãos, matéria seca de plantas, número de dias para emergência, altura das plantas, diâmetro dos colmos das plantas e altura de inserção da primeira espiga. A variável diâmetro do colmo obteve melhor resultado sob a influência de maior lâmina de água, diferente da variável matéria seca de plantas. A inserção da primeira espiga foi afetada pela carga utilizada sobre a roda compactadora durante a semeadura. Quanto maior a carga utilizada, menor é a altura da inserção da primeira espiga. A interação roda x lâmina foi significativa para a variável número de grão.
\end{abstract}

Termos para indexação: Semeadura, engenharia agrícola, mecanização agrícola, Zea mays.

\section{ABSTRACT}

The objective of the present study was to evaluate three models of sowing press wheels, with two levels of vertical load and two irrigation blades during pre- and post-emergence periods of corn seedling. The experiment was carried out at UNESP in the city of Jaboticabal, State of Sao Paulo, Brazil, with complete randomized design (DIC) on a $3 \times 2 \times 2$ factorial scheme, combining three press wheels (plain rubber with groove, plain wheel with vein and double-angled wheel), with two levels of load (162 N and $260 \mathrm{~N}$ ), two water contents $\left(15\right.$ and $\left.19 \mathrm{~mm} \mathrm{day}^{-1}\right)$ and three replicates. The parameters analyzed were: productivity, number of grains in the ear, mass of 100 grains, dry mass of plants, number of days until emergence, plan height, stem diameter of plants and insertion height of the first ear. The variable diameter of stem showed the best result under the influence of a larger water blade, different from the variable dry mass of plants. The insertion of the first ear was affected by the load used on the press wheel during sowing. The heavier the load the lower is the insertion height of the first ear. The wheel-blade interaction was significant or the number of grains variable.

Index terms: Sowing, agricultural engineering, agricultural mechanization, Zea mays.

(Recebido em 13 de janeiro de 2009 e aprovado em 9 de setembro de 2009)

\section{INTRODUÇÃO}

A produção de milho (Zea mays L.) no Brasil, juntamente com a soja, contribui com cerca de $80 \%$ da produção de grãos no País. A diferença entre as duas culturas está no fato de que a soja tem liquidez imediata, dada as suas características de "commodity" no mercado internacional, enquanto que o milho tem sua produção voltada para abastecimento interno. Apesar disso, o milho tem evoluído como cultura comercial, apresentando nos últimos 28 anos, taxas de crescimento da produção de 3,0\% ao ano e da área cultivada de $0,4 \%$ ao ano (Empresa Brasileira de Pesquisa Agropecuária - Embrapa, 2007).

Para obter adequado potencial produtivo das plantas de milho, deve-se atentar para a população desejada, considerando cada tipo de semente, além de que o bom arranjo de plantas é importante para que se obtenha a produtividade satisfatória (Silveira et al., 2005).

O contato das sementes com o solo, dentre elas a do milho, promove trocas de calor e umidade, o que garante germinação eficiente, como a pressão aplicada sobre o solo que pode ou não ser benéfica para a semente; depende do nível de pressão, do desenho e tipo da roda, da umidade no solo e das condições climáticas, entre o período de semeadura e emergência (Cassel et al., 1978). Hummel et al. (1981), citam que a pressão aplicada no solo pelas rodas compactadoras das semeadoras pode ou não ser benéfica para a semente, variando em função de fatores como: carga vertical, formato da roda e umidade no solo, entre outros.

${ }^{1}$ Universidade Federal do Vale do São Francisco/UNIVASF - Rodovia BR 407 - 12 Lote 543 - 56300-000 - Petrolina, PE - jorge.cortez@univasf.edu.br 2Universidade Estadual Paulista "Júlio de Mesquita Filho"/UNESP - Departamento de Engenharia Rural - Jaboticabal, SP 
Grotta et al. (2008) avaliaram a pressão exercida sobre a roda compactadora e concluíram que a compactação no solo na linha de semeadura não interferiu no desenvolvimento da cultura do amendoim. Baseado nisso, a compactação do solo, sobre a semente provoca alterações no ambiente físico, sob o qual a cultura se desenvolve.

Vários autores têm estudado a relação máquinasolo-planta em ensaios de semeadura. Silva et al. (2004) afirmaram que as rodas compactadoras melhoram o contato entre o solo e a semente por meio da aplicação de uma pressão lateral e sobre o sulco de semeadura; e Modolo et al. (2010) afirmam que as rodas provocam leve compactação diretamente sobre as sementes, sem, no entanto, permitir a formação de crostas, favorecendo emergência das plântulas. Silva et al. (2008) ao estudar a influência de rodas compactadoras, profundidades de semeadura e níveis de carga sob a temperatura e o teor de água do solo, verificaram que as rodas com maior área de contato com o solo proporcionaram maiores valores do teor médio de água e da temperatura do solo e que o nível de carga sobre a roda compactadora não afetou a temperatura e o teor de água do solo.

O aumento de contato, proporcionado pela roda compactadora, por meio da aplicação de força lateral e vertical entre o solo e a semente no sulco de semeadura, provoca leve compactação sobre as sementes, com o solo solto o suficiente para facilitar a emergência das plântulas. Além dessa pressão, na operação de semeadura, a profundidade de deposição das sementes pode influenciar a temperatura e umidade disponíveis a semente. A profundidade de deposição da semente deve permitir o contato com o solo úmido e boa germinação (Cortez et al., 2007).

Os poucos trabalhos que tratam dos efeitos da compressão do solo no leito de semeadura, na emergência e no crescimento das plantas, são contraditórios e revelam tanto efeitos positivos na altura de plantas (Smucker \& Erickson, 1989) quanto negativos, atraso e/ou impedimento na emergência (Johnson \& Henry, 1964; Cortez et al., 2006) em relação ao vigor inicial da lavoura.

Cortez et al. (2005) observaram que a compressão gerada pelas rodas compactadoras e por suas respectivas cargas verticais não produz diferença estatística significativa na produtividade de milho, mas existe tendência de cargas acima de $100 \mathrm{~N}$ produzirem melhores resultados de produção de grãos e matéria seca.

Neste trabalho, avaliar a produção de milho para grãos, em função do tipo de roda compactadora, de cargas verticais e por condições de umidade aplicadas durante os períodos de pré e pós-emergência da cultura.

\section{MATERIAL E MÉTODOS}

O experimento foi conduzido na área experimental do Laboratório de Máquinas e Mecanização Agrícola (LAMMA) do Departamento de Engenharia Rural da UNESP Jaboticabal, situada nas coordenadas geodésicas de latitude $21^{\circ} 15^{\prime} \mathrm{S}$ e longitude $48^{\circ} 18^{\prime} \mathrm{W}$, com altitude de $559 \mathrm{~m}$.

O clima da região é classificado, segundo Köeppen, como mesotérmico com inverno seco (Aw) e com chuvas de verão. O solo da área experimental é Latossolo Vermelho eutroférrico típico, A moderado, textura argilosa e relevo suave ondulado, conforme o Sistema Brasileiro de Classificação de Solos (Embrapa, 1999).

A área experimental foi constituída de duas faixas de solo delimitadas por trilhos, dispostas no sentido leste-oeste, cada uma com 1,5 $\mathrm{m}$ de largura por 22,0 $\mathrm{m}$ de comprimento, sendo constituída por parcelas de $1,5 \mathrm{~m}$ x 2,5 m (3,75 $\left.\mathrm{m}^{2}\right)$ que apresentavam intervalos de 1,0 $\mathrm{m}$. Sobre os trilhos, deslocouse trole elétrico, com velocidade constante de $0,37 \mathrm{~m} \mathrm{~s}^{-1}$, no qual é possível acoplar acessórios como: plaina niveladora, sulcador, roda compactadora e equipamentos para irrigação.

O delineamento adotado foi inteiramente casualizado em esquema fatorial $3 \times 2 \times 2$, com profundidade única de semeadura de $0,05 \mathrm{~m}$, três tipos de roda compactadora (Figura 1), duas cargas verticais sobre as rodas (162 e $260 \mathrm{~N}$ ) e duas lâminas de água (15 e 19,5 mm), com três repetições, resultando assim em 36 parcelas.

O preparo do solo foi realizado com enxada rotativa, constituído de faca tipo veloz em trator de rabiças da marca TOBATTA, com potência de 9,42 kW (12 cv), modelo 90, no dia anterior à instalação do experimento com o solo na sua condição friável visando a uniformizar o mesmo. Já, no dia da instalação do experimento, o solo foi nivelado com plaina niveladora acoplada ao trole.

Foi realizado o sorteio das parcelas, e com o uso de sulcador acoplado ao trole, foram abertos sulcos no solo, com profundidade única de $0,05 \mathrm{~m}$, sendo distanciados em 0,45 m. Nos sulcos foram colocadas, manualmente, sementes do cultivar DKB 390 com distância de 0,33 m entre si, que proporciona estande de 67.340 plantas por hectare $\left(3,03\right.$ sementes $\left.\mathrm{m}^{-1}\right)$. Em seguida, os sulcos foram cobertos com o auxílio de régua de madeira e o solo ficou novamente nivelado.

Após o fechamento dos sulcos, foi realizada a compactação do solo sobre as sementes, utilizando-se de três tipos de roda compactadora, acopladas ao trole (Figura 1). Sendo: R1: roda de borracha lisa com estria, massa de $9,950 \mathrm{~kg}$, diâmetro de $24,2 \mathrm{~cm}$ e largura de $17 \mathrm{~cm}$; R2: roda lisa com nervura, massa de $9,550 \mathrm{~kg}$, diâmetro de 22,2 $\mathrm{cm}$ e largura de $9,5 \mathrm{~cm}$; e R3: roda duplo-angulada com massa de $11,525 \mathrm{~kg}$, diâmetro de $24,0 \mathrm{~cm}$ e largura de $2,8 \mathrm{~cm}$. 

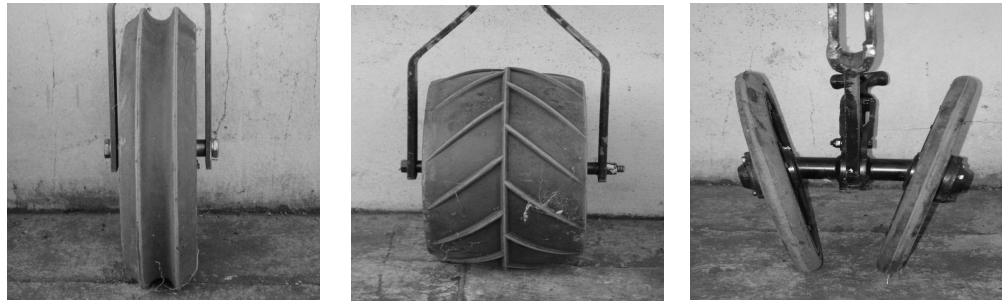

Figura 1 - Modelos de rodas compactadoras utilizadas na compactação do Latossolo Vermelho, na semeadura do milho. Da esquerda para a direita, R1, R2 e R3.

Para se obter as cargas verticais de 162 e $260 \mathrm{~N}$, foram utilizados lastros de chumbo de 5 e $15 \mathrm{~kg}$. A roda compactadora possui, acima de seu eixo, uma extensão vertical que recebe os lastros que são perfurados no centro, fazendo o perfeito encaixe dos mesmos para que não ocorra deslize. As diferenças de massas entre as rodas foram compensadas com a colocação de lastros específicos.

A cultivar utilizada no presente trabalho foi a DKB390, híbrido simples de ciclo precoce, destinado a produção de grãos. Durante o preparo do solo, realizou-se a adubação a lanço, utilizando $350 \mathrm{~kg} \mathrm{ha}^{-1}$, da formulação 10-20-20 (NPK). Para a adubação de cobertura, foi utilizado $1 \mathrm{~kg}$ de uréia por pista, equivalente a $300 \mathrm{~kg} \mathrm{ha}^{-1}$ de $\mathrm{N}$, aplicados na linha das plantas.

O controle fitossanitário da cultura foi efetuado com pulverização para Spodoptera frugiperda (lagarta do cartucho), 28 dias após a semeadura, com os inseticidas Cipermetrina (Cypermethrin) e Match (Lefenuron) com as dosagens de 50-60 e $300 \mathrm{ml} \mathrm{ha}^{-1}$, respectivamente. Para a realização da pulverização, foi utilizada bomba costal e equipamento de proteção individual. Para o controle das plantas daninhas foram realizadas capinas manuais durante todo ciclo da cultura.

Para o cálculo do número médio de dias para a emergência das plântulas foram realizadas contagens nos 10 primeiros dias após a semeadura, sendo considerada emergida a plântula que pudesse ser visualizada sobre a superfície do solo; sendo determinado segundo a metodologia descrita por Edmond \& Drapalla (1958).

A altura das plantas foi determinada no dia da colheita, sendo o padrão utilizado para medida, a distância do solo até a inserção da folha bandeira. $\mathrm{O}$ diâmetro do colmo foi obtido utilizando-se paquímetro digital, e realizadas as medidas acima do ponto de crescimento das raízes adventícias, sendo duas medidas, em razão do formato ovalado do colmo. A altura de inserção da primeira espiga tomou-se a base da espiga até o nível do solo.

Para a obtenção dos valores referentes à produtividade, as espigas foram colhidas e colocadas em sacos de estopa, separados por parcela. Em seguida, foram pesadas com palha e sem palha.

Após a colheita das espigas, uma planta de cada parcela foi coletada (sem raiz) para o cálculo da matéria seca do caule e folhas. As plantas de milho foram coletadas e acondicionadas em sacos de papel, devidamente identificados, e levados para secagem em estufa de ventilação forçada a $60^{\circ} \mathrm{C}$, por 72 horas, até atingir massa constante.

Verificou-se o número de grãos por espiga a partir da contagem do número de fileiras de grãos, multiplicado pelo número de grãos por fileira na espiga antes da debulha. As espigas passaram por um debulhador elétrico e, a partir daí, foram obtidas as massas de 100 grãos. Recipientes de alumínio foram utilizados para colher uma amostra de milho de cada parcela. Essas amostras foram pesadas, obtendose a massa dos grãos úmidos. Em seguida, as amostras foram submetidas a um processo de secagem em estufa com intuito de obter as massas secas dos grãos. Com as massas de cada amostra, antes e após a passagem pela estufa, foi possível calcular a porcentagem de umidade dos grãos.

Os dados foram submetidos à análise de variância e ao teste de comparação de médias de Tukey ao nível de 5\% de probabilidade de erro (Banzatto \& Kronka, 2007).

\section{RESULTADOS E DISCUSSÃO}

\section{Número de dias para emergência}

Observa-se que os fatores roda compactadora, carga vertical e lâmina de água não afetaram de forma significativa ( $\mathrm{P}>0,05)$ o número de dias para emergência (NDE) da cultura do milho (Tabela 1), provavelmente, em razão da lâmina de água aplicada, proporcionou condições adequadas para a semente de milho germinar e emergir adequadamente. Esses resultados são similares aos encontrados por Furlani et al. (2001) que estudaram a cultura do milho em diferentes profundidades de semeadura e cargas similares, sendo de 4,2 o NDE. Essa similaridade entre os resultados ocorreu, em razão das condições climáticas existentes no momento de cada experimento, pois, em ambos, a semeadura foi realizada na mesma época do ano. 
Tabela 1 - Síntese da análise de variância para os valores médios do número de dias para emergência (NDE), altura de plantas, diâmetro do colmo e a altura de inserção da primeira espiga (AIPE) das plantas de milho.

\begin{tabular}{|c|c|c|c|c|}
\hline Fator & NDE (dias) & Altura da planta $(\mathrm{m})$ & Diâmetro do colmo (mm) & AIPE $(\mathrm{cm})$ \\
\hline \multicolumn{5}{|l|}{ Roda compactadora } \\
\hline $\mathrm{R} 1$ - lisa com estria & 4,0 & 2,6 & 27,3 & 99,8 \\
\hline $\mathrm{R} 2$ - lisa com nervura & 4,0 & 2,7 & 26,7 & 103,1 \\
\hline R3 - angulada em V & 4,2 & 2,0 & 27,3 & 100,1 \\
\hline \multicolumn{5}{|l|}{ Carga $(\mathrm{N})$} \\
\hline 162 & 4,2 & 2,8 & 27,2 & $103,1 \mathrm{a}$ \\
\hline 260 & 4,5 & 2,3 & 26,8 & $99,4 \mathrm{~b}$ \\
\hline \multicolumn{5}{|l|}{ Lâmina de água (mm) } \\
\hline 15 & 4,0 & 2,7 & $26,4 \mathrm{a}$ & 101,3 \\
\hline 19,5 & 4,3 & 2,0 & $27,7 \mathrm{~b}$ & 101,2 \\
\hline \multicolumn{5}{|l|}{ Teste F } \\
\hline Rodas (R) & $0,95^{\mathrm{NS}}$ & $1,11^{\mathrm{NS}}$ & $0,45^{\mathrm{NS}}$ & $1,22^{\mathrm{NS}}$ \\
\hline Carga (C) & $2,20^{\mathrm{NS}}$ & $1,57^{\mathrm{NS}}$ & $0,64^{\mathrm{NS}}$ & $4,93 *$ \\
\hline Lâmina (L) & $1,40^{\mathrm{NS}}$ & $2,14^{\mathrm{NS}}$ & $4,99 *$ & $0,00^{\mathrm{NS}}$ \\
\hline $\mathrm{R} \times \mathrm{C}$ & $1,30^{\mathrm{NS}}$ & $0,47^{\mathrm{NS}}$ & $1,14^{\mathrm{NS}}$ & $0,40^{\mathrm{NS}}$ \\
\hline $\mathrm{R} \times \mathrm{L}$ & $2,10^{\mathrm{NS}}$ & $2,37^{\mathrm{NS}}$ & $0,02^{\mathrm{NS}}$ & $0,62^{\mathrm{NS}}$ \\
\hline $\mathrm{C} \times \mathrm{L}$ & $1,35^{\mathrm{NS}}$ & $0,76^{\mathrm{NS}}$ & $0,58^{\mathrm{NS}}$ & $1,63^{\mathrm{NS}}$ \\
\hline $\mathrm{R} \times \mathrm{C} \times \mathrm{L}$ & $0,75^{\mathrm{NS}}$ & $0,27^{\mathrm{NS}}$ & $0,32^{\mathrm{NS}}$ & $0,63^{\mathrm{NS}}$ \\
\hline C.V. (\%) & 15,8 & 4,7 & 6,7 & 4,9 \\
\hline
\end{tabular}

Ns: não significativo $(\mathrm{P}>0,05)$; $^{*}$ : significativo $(\mathrm{P} \leq 0,05)$; $^{* *}$ : significativo $(\mathrm{P} \leq 0,01)$, C.V.: coeficiente de variação.

Como o solo foi mantido sob irrigação durante a condução do experimento, o fato de o nível de carga e suas interações não terem afetado a emergência das plântulas de milho, pode ser explicado pela alta umidade do solo. Johnson \& Buchele (1961) afirmaram que o solo seco e compactado oferece resistência considerável na emergência das plântulas de milho, enquanto Johnson \& Henry (1964) observaram que a carga do solo atrasou, ou impediu a emergência do milho, exceto para o caso de a zona compactada ser mantida com alta umidade no solo, o que diminuiria a força de resistência do mesmo.

\section{Altura da planta, diâmetro do colmo e altura da inserção da primeira espiga}

Observa-se que não ocorreu efeito na diferença $(\mathrm{P}>0,05)$ de altura das plantas de milho pelos tratamentos propostos (Tabela 1), indicando que não ocorre influência das rodas compactadoras, cargas verticais ou lâminas de água na conformação de altura de plantas de milho. Como a avaliação foi realizada próxima à colheita, após o estádio reprodutivo, Viégas \& Peeten (1987) afirmam que, quando a planta se aproxima do estádio reprodutivo, se o ambiente for propício, a tendência é de todas as plantas se igualarem, pois a conformação final da planta é determinada geneticamente.

Silva et al. (2004) encontraram pequena diferença entre as alturas das plantas em diversos estádios de desenvolvimento, com diferentes modelos de roda compactadora, cargas verticais e profundidades de semeadura.

Analisando o diâmetro dos colmos, pode-se encontrar diferença significativa $(\mathrm{P} \leq 0,05)$ nos resultados, tratando-se do fator lâmina de água. Sendo que na aplicação da maior quantidade de água, encontrou-se maior diâmetro de colmo. Já que a dose de adubo aplicada nas parcelas foi a mesma, as condições climáticas foram basicamente iguais para todos os tratamentos, conclui-se que a maior quantidade de água no início do ciclo da cultura de milho contribuiu para o desenvolvimento do colmo, o que contribui para menor acamamento.

A altura de inserção da primeira espiga foi influenciada pelo fator carga $(\mathrm{P} \leq 0,05)$. Quanto maior a carga aplicada, menor é a altura de inserção da primeira espiga, resultante da maior compactação da semente durante a semeadura. 


\section{Produtividade}

Não ocorreu diferença $(\mathrm{P}>0,05)$ nas médias de produtividade da cultura do milho (Tabela 2) para os fatores testados, sendo a média de $11.042 \mathrm{~kg} \mathrm{ha}^{-1}$. Silva et al. (2004) utilizando os fatores roda compactadora, carga vertical sobre a roda e profundidade de semeadura, observou diferenças significativas apenas para a profundidade de semeadura, o que afetou o desenvolvimento vegetativo das plantas de milho.

Tratando-se da necessidade de água para a cultura do milho, pode-se dizer que o período de máxima exigência é na fase do embonecamento ou um pouco depois dele. Por isso, déficits de água que ocorrem nesse período são os que provocam maiores reduções de produtividade. Déficit anterior ao embonecamento reduz a produtividade em 20 a 30\%; no embonecamento em 40 a 50\% e após em 10 a 20\% (Embrapa, 2006). A extensão do período de déficit também é importante. Durante o início do cultivo do milho, houve variação da quantidade de água aplicada, porém, as precipitações foram bem frequentes durante a fase final do ciclo, motivo esse que explica o fato de que o fator lâmina de água ser não significativo $(\mathrm{P}>0,05)$ para os resultados da produtividade.

\section{Massa de 100 grãos e matéria seca de plantas}

Não houve $(\mathrm{P}>0,05)$ variação da massa de 100 grãos da cultura do milho, provavelmente por este fator ser determinado geneticamente.

Os tratamentos que receberam menor quantidade de água durante o período de semeadura e algumas semanas depois dessa, apresentaram maior $(\mathrm{P} \leq 0,01)$ quantidade de matéria seca. Esses resultados discordam da Embrapa (2006), que cita o milho como uma das culturas que demanda muita água e, assim, produz grande quantidade de matéria seca por unidade de água absorvida.

Para a matéria seca, Silva et al. (2004) ao trabalhar com cargas verticais e profundidade da semeadura do milho, avaliou a quantidade de matéria seca do milho aos vinte e um dias, e o autor não encontrou diferença para estes fatores. Cortez et al. (2005), ao trabalharem com avaliação de cargas verticais, encontraram produção média de $9.050 \mathrm{~kg} \mathrm{ha}^{-1}$ na produção de matéria seca ao final do ciclo do milho.

Tabela 2 - Síntese da análise de variância para os valores médios da produtividade, massa de 100 grãos, número de grãos por espiga e matéria seca de plantas do milho.

\begin{tabular}{|c|c|c|c|c|}
\hline Fator & $\begin{array}{l}\text { Produtividade } \\
\quad\left(\mathrm{kg} \mathrm{ha}^{-1}\right)\end{array}$ & $\begin{array}{l}\text { Massa de } 100 \\
\text { grãos }(\mathrm{g})\end{array}$ & $\begin{array}{l}\text { Matéria seca de plantas } \\
\qquad\left(\mathrm{kg} \mathrm{ha}^{-1}\right)\end{array}$ & $\begin{array}{l}\text { Número de grãos } \\
\text { por espiga }\end{array}$ \\
\hline \multicolumn{5}{|l|}{ Roda compactadora } \\
\hline $\mathrm{R} 1$ - lisa com estria & 10.506 & 0,04 & 12.037 & 588,2 \\
\hline R2 - lisa com nervura & 11.217 & 0,04 & 12.121 & 640,8 \\
\hline $\mathrm{R} 3$ - angulada em V & 11.403 & 0,04 & 10.914 & 611,0 \\
\hline \multicolumn{5}{|l|}{ Carga $(\mathrm{N})$} \\
\hline 162 & 11.573 & 0,04 & 11.148 & 612,22 \\
\hline 260 & 10.511 & 0,04 & 12.233 & 614,44 \\
\hline \multicolumn{5}{|l|}{ Lâmina de água (mm) } \\
\hline 15 & 10.807 & 0,04 & $12.944 \mathrm{a}$ & 639,22 \\
\hline 19,5 & 11.277 & 0,04 & $10.437 \mathrm{~b}$ & 587,44 \\
\hline \multicolumn{5}{|l|}{ Teste F } \\
\hline Rodas (R) & $0,60^{\mathrm{NS}}$ & $1,50^{\mathrm{NS}}$ & $0,76^{\mathrm{NS}}$ & $3,99 *$ \\
\hline Carga (C) & $2,23^{\mathrm{NS}}$ & $0,17^{\mathrm{NS}}$ & $1,49^{\mathrm{NS}}$ & $0,02^{\mathrm{NS}}$ \\
\hline Lâmina (L) & $0,44^{\mathrm{NS}}$ & $0,17^{\mathrm{NS}}$ & $7,93 * *$ & $11,50 * *$ \\
\hline $\mathrm{R} \times \mathrm{C}$ & $0,31^{\mathrm{NS}}$ & $1,17^{\mathrm{NS}}$ & $3,35^{\mathrm{NS}}$ & $0,97^{\mathrm{NS}}$ \\
\hline $\mathrm{R} \times \mathrm{L}$ & $0,10^{\mathrm{NS}}$ & $1,17^{\mathrm{NS}}$ & $2,40^{\mathrm{NS}}$ & $4,28 *$ \\
\hline $\mathrm{C} \times \mathrm{L}$ & $0,35^{\mathrm{NS}}$ & $0,17^{\mathrm{NS}}$ & $0,40^{\mathrm{NS}}$ & $2,80^{\mathrm{NS}}$ \\
\hline $\mathrm{R} \times \mathrm{C} \times \mathrm{L}$ & $0,10^{\mathrm{NS}}$ & $1,17^{\mathrm{NS}}$ & $1,20^{\mathrm{NS}}$ & $1,51^{\mathrm{NS}}$ \\
\hline C.V. $(\%)$ & 19,3 & 4,7 & 22,8 & 7,5 \\
\hline
\end{tabular}

Ns: não significativo $(\mathrm{P}>0,05){ }^{*}$ : significativo $(\mathrm{P} \leq 0,05) ;{ }^{* *}$ : significativo $(\mathrm{P} \leq 0,01)$, C.V.: coeficiente de variação. 


\section{Número de grãos por espiga}

Para o número de grãos por espiga (Tabela 2), ocorreu diferença significativa para rodas $(\mathrm{P} \leq 0,05)$, lâminas $(\mathrm{P} \leq 0,01)$ e a interação rodas e lâminas $(\mathrm{P} \leq 0,05)$.

$\mathrm{Na}$ Tabela 3, são apresentados os resultados do desdobramento da interação entre os fatores roda e lâmina de água para variável número de grãos. Observa-se que para lâmina $1(15 \mathrm{~mm})$ dentro das três rodas, que a roda lisa com nervura (R2) apresentou a maior quantidade de grãos, enquanto que a roda lisa com estria o obteve o menor número de grãos. Provavelmente, a R2 por apresentar nervuras em ângulo inibem o selamento superficial do solo, que favorece a infiltração de água e, consequentemente, há maior disponibilidade de águas as plantas. Na lâmina $2(19,5 \mathrm{~mm})$ não se observou diferença entre as rodas.

A roda lisa com estria (R1) e a roda angulada em V (R3) não apresentaram diferença nas lâminas avaliadas. No entanto, a roda lisa com nervura apresentou maior número de grãos por espiga na lamina de água com $15 \mathrm{~mm}$.

Tabela 3 - Desdobramento da interação entre os fatores rodas e lâminas de água para o número médio de grãos por espiga na cultura do milho.

\begin{tabular}{lcc}
\hline \multirow{2}{*}{ Fatores } & \multicolumn{2}{c}{ Número de grãos por espiga } \\
\cline { 2 - 3 } & \multicolumn{2}{c}{ Lâmina de água $(\mathrm{mm})$} \\
\cline { 2 - 3 } R1 - lisa com estria & $589,7 \mathrm{~A} \mathrm{~b}$ & 19,5 \\
R2 - lisa com nervura & $696,3 \mathrm{~A} \mathrm{a}$ & $585,7 \mathrm{~A} \mathrm{a}$ \\
R3 - angulada em V & $631,7 \mathrm{~A} \mathrm{ab}$ & $590,0 \mathrm{~A} \mathrm{a}$ \\
\hline
\end{tabular}

Letras iguais, maiúscula na linha e minúscula na coluna não diferem entre si pelo teste de Tukey a $5 \%$ de probabilidade.

\section{CONCLUSÕES}

Tratando-se apenas do fator lâmina de irrigação, concluiu-se que para o maior diâmetro do colmo, é necessária a aplicação de maior lâmina (19,5 mm). Já, a matéria seca das plantas de milho obtém melhor resposta com a utilização de menor lâmina $(15 \mathrm{~mm})$.

O fator carga vertical aplicada nas rodas compactadoras influencia a altura de inserção da primeira espiga, em que se percebe maior a carga aplicada $(260 \mathrm{~N})$ ocorre menor altura de inserção da primeira espiga, resultante da maior compactação durante a semeadura.

$\mathrm{O}$ fator rodas compactadoras influenciou o número de grãos na espiga, juntamente com as lâminas de irrigação, e obtém maior número de grãos na espiga com a utilização de roda lisa com nervuras aliadas à lâmina de 15 mm de irrigação.

A massa de 100 grãos, o número de dias para emergência, a altura da planta e a produtividade não são influenciados por nenhum dos fatores estudados.

\section{REFERÊNCIAS BIBLIOGRÁFICAS}

BANZATTO, D.A.; KRONKA, S.N. Experimentação agrícola. Jaboticabal: Funep, 2007. 245p.

CASSEL, P.K.; BOWEN, H.D.; NELSON, L.A. Na evolution of mechanical impedance of three tillage treatments on Norfolk Loamy Sand. Soil Science of America Journal, Madison, v.42, p.116-120, 1978.

CORTEZ, J.W.; CARVALHO FILHO, A.; SILVA, R.P. da; FURLANI, C.E.A.; SIMONIS, D.B. Comportamento da cultura do sorgo em função do tipo de rodas compactadoras e cargas verticais impostas na operação de semeadura. Engenharia Agrícola, Jaboticabal, v.26, n.2, p.461-469, 2006.

CORTEZ, J.W.; FURLANI, C.E.A.; SILVA, R.P.; CARVALHO FILHO, A. Pressão certa. Cultivar Máquinas, Pelotas, n.45, p.6-8, 2005.

CORTEZ, J.W.; SILVA, R.P.; CARVALHO FILHO, A.; FURLANI, C.E.A.; FREITAS, S.S. Avaliação da influência de cargas verticais sobre diferentes rodas compactadoras no ciclo de semeadura do milho. Ciência e Agrotecnologia, Lavras, v.31, n.4, p.11551160, 2007.

EDMOND, J.B.; DRAPALLA, W.J. The effects of temperature, sand and soil, and acetone on germination of okra seeds. Proceedings of the American Society for Horticultural Science, Alexandria, v.71, p.428-434, 1958.

\section{EMPRESA BRASILEIRA DE PESQUISA}

AGROPECUÁRIA. Sistema brasileiro de classificação dos solos. Rio de Janeiro: EMBRAPA/CNPSO, 1999. 412p.

\section{EMPRESA BRASILEIRA DE PESQUISA} AGROPECUÁRIA. Viabilidade e manejo da irrigação da cultura do milho. Disponível em: <http:// iwww.cnpms.embrapa.br/publicacoes/publica/200 $\overline{6}$ / Circulares\%20tecnicas/Circular\%2085.pdf Acesso em: 9 maio 2006 . 
EMPRESA BRASILEIRA DE PESQUISA AGROPECUÁRIA. Mercado e comercialização do milho. Disponível em: Shttp://WwW.cnpms.embrapa.bri pubblicacoes/milho/mercado.htm . Acesso em: 9 maio de 2007.

FURLANI, C.E.A.; LOPES, A.; REZENDE, L.C.; SILVA, S.S.S.; LEITE, M.A.S. Influência da compactação do solo na emergência das plântulas de milho a diferentes profundidades de semeadura. Engenharia na

Agricultura, Viçosa, v.9, n.3, p.147-153, 2001.

GROTTA, D.C.C.; FURLANI, C.E.A.; SILVA, R.P.; REIS, G.N.; CORTEZ, J.W.; ALVES, P.J. Influência da profundidade de semeadura e da compactação do solo sobre a semente na produção de amendoim. Ciência e Agrotecnologia, Lavras, v.32, n.2, p.547-552, 2008.

HUMMEL, J.W.; GRAY, L.E.; NAVE, W.R. Soybean emergence from field seedbed environments.

Transaction of ASAE, Saint Joseph, v.24, n.4, p.872-878, 1981.

JOHNSON, W.J.; BUCHELE, W.F. Influence of soil granule size and compaction on rate of soil drying and emergence of corn. Transactions of the ASAE, Saint Joseph, v.4, n.2, p.170-174, 1961.

JOHNSON, W.H.; HENRY, J.E. Influence of simulated row compactation on seeding emergence and soil deying nates. Transactions of the ASAE, Saint Joseph v.7, n.3, p.252-255, 1964.

MODOLO, A.J.; TROGELLO, E.; NUNES, A.L.; FERNANDES, H.C.; SILVEIRA, J.C.M.; DAMBROS, M.P. Efeito de cargas aplicadas e profundidades de semeadura no desenvolvimento da cultura do feijão em sistema plantio direto. Ciência e Agrotecnologia, Lavras, v.34, n.3, p.739-745, 2010.

SILVA, R.P.; CORA, J.E.; CARVALHO FILHO, A.; LOPES, A.; FURLANI, C.E.A. Efeito de rodas compactadoras submetidas a cargas verticais em profundidades de semeadura sobre o desenvolvimento do milho.

Engenharia na Agricultura, Jaboticabal, v.24, n.2, p.309319, 2004.

\section{SILVA, R.P.; CORA, J.E.; CARVALHO FILHO, A.;}

FURLANI, C.E.A.; LOPES, A. Efeito da profundidade de semeadura e de rodas compactadoras submetidas a cargas verticais na temperatura e no teor de água do solo durante a germinação de sementes de milho. Ciência e Agrotecnologia, Lavras, v.32, n.3, p.929-937, 2008.

SILVEIRA, J.C.M.; GABRIEL FILHO, A.; TIEPPO, R.C.; TORRES, D.G.B.; BALDESSIN, A.; BOLIGON, F.

Uniformidade de distribuição de plantas e estande de milho (Zea mays L.) em função do mecanismo dosador de sementes. Acta Scientiarum Agronomy, Maringá, v.27, n.3, p.467-472, 2005.

SMUCKER, A.J.M.; ERICKSON, A.E. Tillage and compactive modifications of gaseous flow and soil aeration. In: LARSON, W.E.; BLAKE, G.R.; ALLMARAS, R.R.; VOORHEES, W.B.; GUPTA, S.C. (Eds.). Mechanics related process in structured agricultural soils. The Netherlands: Kluwer Academic, 1989. p.205-221.

VIÉGAS, G.P.; PEETEN, H. Sistemas de produção. In: PATERNIANI, E.; VIÉGAS, G.P. (Eds.). Melhoramento e produção do milho. Campinas: Fundação Cargill, 1987. p.453-538. 